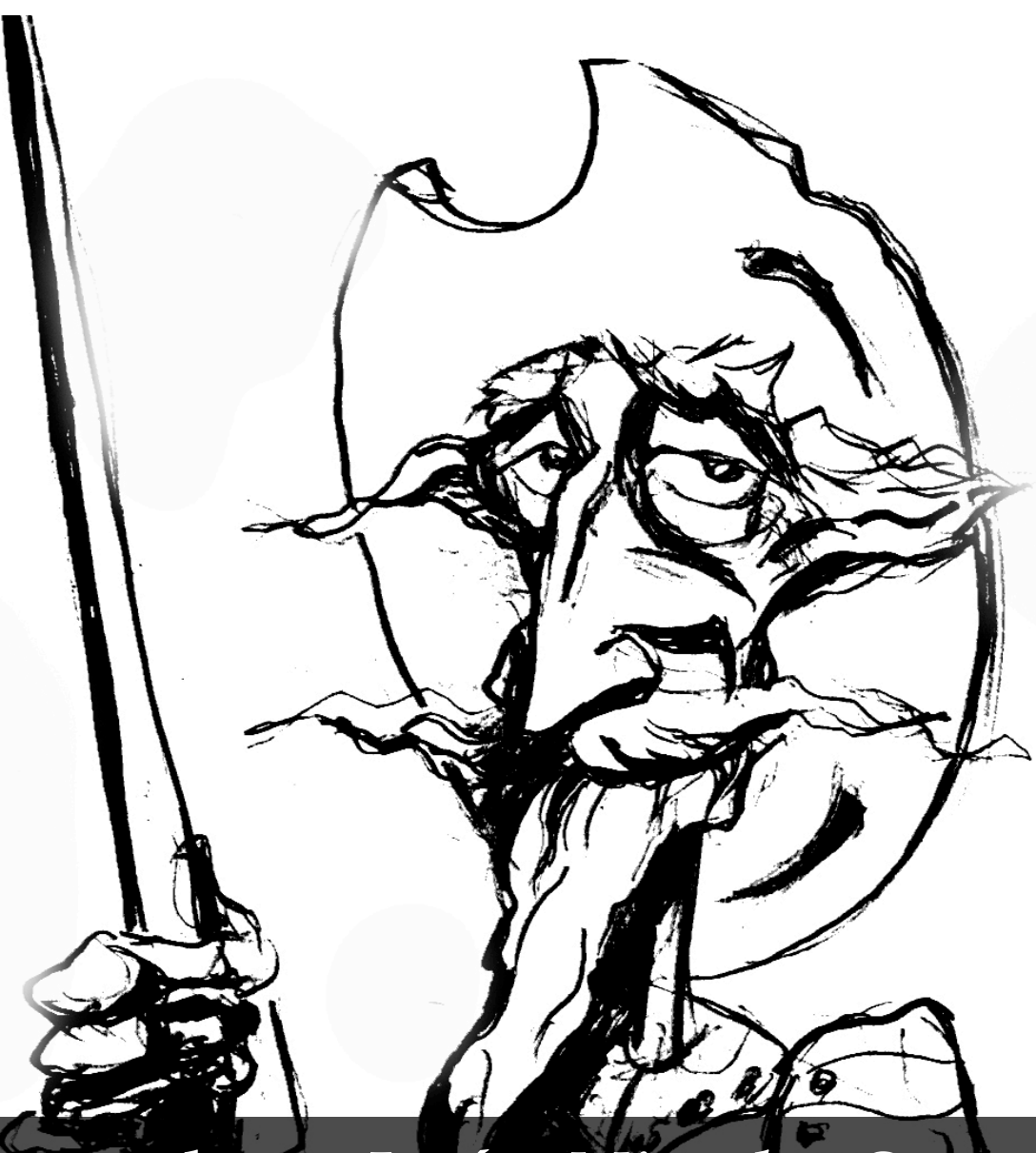

Discusión sobre José Miguel carrera. Un revolucionario chileno en el Río de la Plata de Beatriz Bragoni.

[Dante Palma Alvarado, Sergio Serulnikov, Beatriz Bragoni] 


\title{
Comentario al libro José Miguel Carrera. Un revolucionario chileno en el Río de la Plata de Beatriz Bragoni (Edhasa, Buenos Aires, 2012)
}

\author{
Commentary on Jose Miguel Carrera. A Chilean revolutionary in the Rio de la \\ Plata by Beatriz Bragoni (Edhasa, Buenos Aires, 2012)
}

DANiel Palma Alvarado

\section{Resumen}

El texto analiza algunos aspectos de la trayectoria del chileno José Miguel Carrera en el marco de la revolución independentista, a partir de la biografía escrita por Beatriz Bragoni. Destaca los aportes más novedosos del trabajo de la autora y problematiza una serie de temáticas que cobran relevancia a la luz de las peripecias de este caudillo en el cono sur americano entre 1810 y 1821.

Palabras clave: Chile - Independencia - José Miguel Carrera - caudillos - biografía

\begin{abstract}
The article analyzes some aspects of Chilean Jose Miguel Carrera's path in the context of the independence revolution, considering the biography written by Beatriz Bragoni. It highlights the most innovative contributions of the author's work and discusses a number of issues that become relevant in the light of the political vicissitudes of this leader in America's southern cone between 1810 and 1821 .
\end{abstract}

Keywords: Chile - Independence - José Miguel Carrera - caudillos - biography

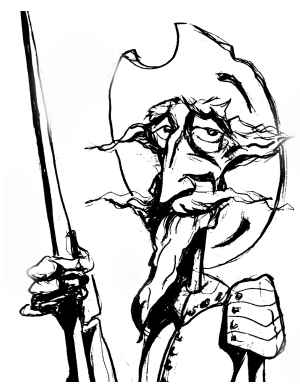

Recibido con pedido de publicación el 5 de octubre de 2016

Aceptado para su publicación el 30 de octubre de 2016

Versión definitiva recibida el 15 de noviembre de 2016

Daniel Palma Alvarado, Departamento de Historia, Universidad Alberto Hurtado (UAH), Chile; e-mail: dpalma@uahurtado.cl

Palma Alvarado, Daniel “Comentario al libro José Miguel Carrera. Un revolucionario chileno en el Río de la Plata de Beatriz Bragoni (Edhasa, Buenos Aires, 2012)”, Prohistoria, Año XIX, núm. 26, dic. 2016, pp. 105110. 
Agradezco en primer lugar la invitación a participar de esta actividad de debate historiográfico y la iniciativa de Jorge Gelman y Raúl Fradkin de convocarnos a realizar este ejercicio, que nos permite cruzar agendas de investigación sobre los liderazgos surgidos en el contexto de las revoluciones de independencia en el Río de la Plata y Chile. Me corresponde comentar el libro de Beatriz Bragoni, aunque debo aclarar de entrada que no soy un especialista en José Miguel Carrera ni mucho menos. Mis observaciones, por lo tanto, son las de un lector curioso y entrometido, cuya aproximación al período se ha realizado principalmente desde la historia social del delito y de las prácticas judiciales.

Pertenezco a una generación que creció bajo la dictadura de Pinochet, enarbolando a José Miguel Carrera como un ícono de la revolución y de la lucha contra el autoritarismo, expresado en su impugnación al gobierno de Bernardo O’Higgins y al papel de la Logia Lautarina. Un José Miguel Carrera mártir, que fue perseguido y, finalmente, fusilado en Mendoza en 1821 por sus archienemigos, quienes colmaron su actuación de imágenes negativas, atribuidas las más de las veces a una personalidad compleja y oportunista (era el "monstruo de América", como lo llamó San Martín o el "genio de la discordia" según Dorrego). En cambio para nosotros, Carrera representaba al líder radical por antonomasia, ocupando un lugar incómodo en el panteón de héroes nacionales chilenos, relegado a un plano secundario por aquellos que consolidaron el triunfo de las armas patriotas en los campos de batalla.

Solo a raíz de la conmemoración del bicentenario de las independencias la estatua de José Miguel Carrera fue trasladada desde un sector más bien retirado del centro cívico de Santiago hacia la Plaza Bulnes, justo al frente de la casa de gobierno donde se ubica la estatua de O'Higgins, el "padre de la patria". Hoy, ambos se encuentran nuevamente uno frente al otro. Este traslado simboliza, desde luego, la voluntad de reconocer al principal caudillo de la "patria vieja" el papel que desempeñó en aquellos convulsionados años. De ahí también lo interesante del desafío de hacer un comentario a la obra de Bragoni que tensiona las visiones dominantes y analiza al prócer desde una perspectiva más amplia, como protagonista estelar de las dinámicas políticas regionales de la época.

El libro se plantea como una biografía política, invocando su "potencialidad explicativa e interpretativa... que privilegia al actor y sus prácticas, y el espacio social que las organiza y contribuye a capturar sus significados" (p. 24); propone explicar los vaivenes del proceso revolucionario a partir de las "relaciones entre individuo y sociedad, entre individuo e institución, entre individuo y poder"; es, entonces, mucho más que una biografía en el sentido tradicional, al articularse en torno a preguntas relevantes sobre la política en tiempos de revolución que contribuyen a desmontar las mitificaciones propias de la historiografía patriótica del siglo XIX. La estrategia narrativa es la de iluminar el contexto revolucionario a partir de las 
experiencias del personaje, pero evitando la trampa en que han caído muchas obras sobre Carrera donde "lo personal invade lo político" (p. 17).

La investigación es muy contundente. Se nutre de la documentación de archivos españoles (AGI-Chile), chilenos (archivo O'Higgins, Colección de Historiadores y de Documentos de la Independencia, CHDI) y argentinos (AGN, Documentos de San Martín, AGM de Mendoza), además de prensa, escritos de viajeros y numerosos documentos incluidos en obras clásicas del siglo XIX. Por otra parte, incorpora una amplia bibliografía especializada, transnacional y actualizada, dialogando con los enfoques y problemas que han dinamizado este campo en los últimos años. El impresionante barrido de fuentes, sumado al trabajo previo de la autora sobre el período, garantizan un producto de calidad indiscutida.

Me referiré a tres aspectos que constituyen aportes valiosos de este libro por la novedad que representan en relación a aproximaciones precedentes. En primer lugar, Bragoni es muy clara al señalar el perfil controvertido de José Miguel Carrera en la historiografía chilena y argentina y reacciona ante la "imagen cuasi petrificada del desempeño político del caudillo chileno en el curso revolucionario sudamericano" (p. 16). Su objetivo será, entonces, la reconstrucción de la trama de relaciones políticas, las tensiones y enfrentamientos entre los revolucionarios, pero sin quedar atrapada ni abanderizarse por ninguna de las versiones más arraigadas, las que aún siguen replicando los antagonismos del siglo XIX (carreristas vs. o'higginistas). ${ }^{1}$

Superando esta aporía, la autora remite a la "imprevisibilidad de la revolución" como problema fundamental de la política del período, que habría alimentado las contradicciones generadas entre las distintas fuerzas $y$ sensibilidades en disputa. El libro describe la profundidad de las rivalidades, revelando momentos en que incluso se puso en riesgo objetivos mayores, como cuando San Martín desvió "hombres, armas y municiones" destinados a la campaña del Perú para combatir a Carrera (p. 274) o cuando este último buscó apoyos en grupos con lealtades opuestas al proyecto emancipador, como los "indios realistas" que fueron convocados a sumarse a sus tropas (pp. 253-256) o los intercambios epistolares con el célebre montonero realista Vicente Benavides (p. 265). Todo esto da cuenta de la dificultad de lograr consensos mínimos duraderos o de transar en pos de las metas comunes.

Al mismo tiempo, las pugnas y purgas al interior de las fuerzas revolucionarias obligaron a los jefes a tener que desplegar permanentemente grandes esfuerzos para legitimar su accionar, construyendo alianzas y apelando a identidades territoriales y políticas explícitamente diferenciadas de sus

\footnotetext{
${ }^{1}$ Es el caso del "Instituto de Investigaciones Históricas José Miguel Carrera", que funciona desde 1948, y del "Instituto O'Higginiano de Chile", creado en 1953, cuyas actividades y estudios todavía se desarrollan en base a la negación o degradación del adversario histórico.
} 
adversarios. Nadie tuvo el camino abonado. Es sintomática, en ese sentido, la temprana autoafirmación de Carrera como cabecilla de un "ejército chileno" y, en contrapartida, su catalogación de "extranjero" en el Río de la Plata. De esta manera, el libro logra develar el complejo proceso de formación de nuevas identidades políticas en el contexto de desmoronamiento del orden colonial.

Una segunda cuestión novedosa que Bragoni instala en la discusión es la del "peso de la justicia revolucionaria". A partir del juicio contra Juan José y Luis Carrera en los primeros meses de 1818, desarrolla una labor de "orfebrería" -como la denomina la autora de una reseña a este libro- que da cuenta de la intrincada relación entre justicia y política en la coyuntura independentista. ${ }^{2}$ Bragoni da en el clavo al plantear esta problemática que en los últimos años ha motivado el florecimiento de investigaciones sobre la historia social y política de la justicia en el tránsito desde régimen colonial al republicano.

Advertimos el temprano afán de los gobernantes por monopolizar las labores judiciales y policiales, según lo han ilustrado autores como Osvaldo Barreneche, y su utilización para neutralizar a los disidentes. La justica emerge, entonces, como una extensión de las disputas políticas, un campo de batalla con lógicas propias que es preciso estudiar más ampliamente como parte de las dinámicas de la guerra. Los criterios de selección de los jueces y fiscales, las atribuciones y condiciones en que operaron las defensas de los acusados, el proceso judicial, las penas y la ejecución de las sentencias; son todos aspectos que a la luz del trabajo de Bragoni se vuelve imperativo visitar a fondo y así descifrar el funcionamiento de una de las modalidades de resolución de conflictos menos estudiada en el contexto revolucionario.

Posiblemente, el aspecto más original de este libro para los lectores chilenos sea la recreación minuciosa del itinerario de José Miguel Carrera en el Río de la Plata. La autora realiza un completo análisis de las peripecias del caudillo desde que llegó a Mendoza en 1814 hasta que, de regreso de su viaje a los EEUU y marginado del Ejército Libertador de los Andes, inició su diáspora por distintas provincias del antiguo virreinato en busca de aliados. En este deambular afloran una serie de facetas poco conocidas del carácter y del liderazgo de este hombre, las que a la fecha no habían sido sistematizadas.

Un capítulo particularmente interesante es el que aborda la "guerra de papeles" que Carrera, al frente de la Imprenta Federal, encabezó desde Montevideo y Entre Ríos contra los “directoriales”. Según demuestra la autora, el chileno destacó como polemista y redactor de pluma punzante del periódico “El Hurón” entre 1818 y 1819, además de ser el autor de virulentas proclamas y manifiestos en contra de sus enemigos y detractores. Esta labor habría sido

\footnotetext{
2 Véase la reseña de Lucrecia Enríquez en revista Historia, vol. 46 núm. 1, Instituto de Historia Pontificia, Universidad Católica de Chile, Santiago de Chile, junio 2013, pp. 243-247.
} 
clave para erosionar el poder de Pueyrredón y compañía, convirtiendo a Carrera en factor de la política rioplatense antes de devenir montonero. Los valiosos indicios que se aportan en el libro sobre las actividades del exiliado chileno en el marco de los enfrentamientos interprovinciales del Río de la Plata permiten entender ese influjo -escasamente divulgado en Chile-, hasta que en 1820 su estrella declinó.

Del mismo modo, Bragoni reconstruye notablemente el creciente aislamiento de Carrera y el endurecimiento en su apelación a los "chilenos" y al "ejército chileno" para derrocar a un gobernador "extranjero" como San Martín. El gran problema, como lo hace notar la autora, fue el hecho de que se trató de un "liderazgo sin poder" que a la postre le valió el abandono de sus aliados, al mismo tiempo que denota los límites en la colaboración entre jefes con visiones muy diferentes sobre las urgencias coyunturales y el tipo de orden a establecer.

Para terminar, me gustaría mencionar una problemática que sería importante ahondar. Las aproximaciones más conocidas a la figura de José Miguel Carrera resaltan su contribución a la radicalización de la revolución independentista y su republicanismo de cuño liberal, además de la "reafirmación de la identidad chilena frente a la americana" (B. Vicuña Mackenna). Sin embargo, subsiste la pregunta por el componente social de su liderazgo y su visión del cambio social. ¿En qué medida la coincidencia de Carrera con los caudillos federales, con los artiguistas y el "sistema de los pueblos libres", implicó tomas de posición frente a las iniciativas más radicales en materia social? ¿Cuál fue su ideario respecto a la cuestión de la tierra, la ampliación de la ciudadanía o la abolición de la esclavitud? En cuanto a la esclavitud, por ejemplo, en el libro se menciona que Carrera liberó a su última esclava en 1819 (p. 219), cuando ya no contaba con los recursos de antaño, pero no sabemos si aquello obedeció exclusivamente a razones prácticas del momento o a convicciones más profundas acerca del orden social.

Por otra parte, autores como Julio Pinto sugieren que la invocación al bajo pueblo por parte de José Miguel Carrera, salvo en el plano militar, “...nunca adquirió un carácter sistemático o de verdadero reconocimiento social, y que cuando llegó a valerse de tales apoyos fue sólo como un instrumento para desequilibrar las pugnas que se desarrollaban al interior de la élite". También que "no puede identificarse en él una política social propiamente dicha, o un afán de transformar al bajo pueblo en sujeto político". ${ }^{3}$ En efecto, en sus proclamas, sobre todo después del fusilamiento de sus hermanos en 1818, Carrera se dirigió siempre a un pueblo muy vagamente

\footnotetext{
${ }^{3}$ La primera cita es del artículo "El rostro plebeyo de la independencia chilena, 1810-1830", en Nuevo Mundo Mundos Nuevos, París, 2010, http://nuevomundo.revues.org/59660); y la otra del libro ¿Chilenos todos? La construcción social de la nación, 1810-1840 (en coautoría con Verónica Valdivia, LOM, Santiago de Chile, 2009), p. 35.
} 
definido en términos sociales -los "habitantes libres" de Chile- con la promesa de combatir la subordinación a Buenos Aires. Pero ¿qué más podía o estuvo dispuesto a ofrecer? Creo que esta dimensión habría que explorarla más.

Finalmente, sin perjuicio de que en lo personal mis lecturas del tema son limitadas, me parece que este libro es la mejor versión de la vida de José Miguel Carrera que se ha escrito. Pero también es más que eso, pues se apropia de su figura para presentar un marco explicativo más rico de la política en tiempos de revolución, cumpliendo con el propósito señalado en la introducción al incitar la problematización de una serie de aspectos fundamentales de esos turbulentos años hasta ahora bastante opacados.

Santiago de Chile, junio de 2016 